\title{
Straw particle size in calf starters: Effects on digestive system development and rumen fermentation ${ }^{1}$
}

\author{
F. X. Suarez-Mena, ${ }^{*}$ A. J. Heinrichs,${ }^{* 2}$ C. M. Jones, ${ }^{*}$ T. M. Hill, $†$ and J. D. Quigley† \\ *The Pennsylvania State University, University Park 16802 \\ †Provimi North America, Brookville, OH 45309
}

\begin{abstract}
Two trials were conducted to determine effects of straw particle size in calf starter on rumen fermentation and development in calves. Holstein calves $(\mathrm{n}=17$ in trial $1 ; \mathrm{n}=25$ in trial 2) were housed in individual pens; bedding (wood shavings) was covered with landscape fabric to completely avoid consumption of bedding. Milk replacer was fed at $12 \%$ of birth body weight per day and water offered free choice. Calves were randomly assigned to 4 treatments differing in geometric mean particle length $\left(\mathrm{X}_{\mathrm{gm}}\right)$ of straw comprising $5 \%$ of starter dry matter. Straw was provided within the pellet at manufacture (PS; $0.82 \mathrm{~mm} \mathrm{X}_{\mathrm{gm}}$ ) or mixed with the pellet at time of feeding at $\mathrm{X}_{\mathrm{gm}}$ of 3.04 (SS), 7.10 (MS), or $12.7(\mathrm{LS}) \mathrm{mm}$. Calves ( $\mathrm{n}=12 ; 3$ /treatment) in trial 1 were fitted with a rumen cannula by wk 2 of age. A fixed amount of starter that was adjusted with age and orts were fed through the cannula in cannulated calves. Calves were euthanized 6 wk after starter was offered (9 and 7 wk of age for trials 1 and 2, respectively). Rumen digesta $\mathrm{pH}$ linearly decreased with age, whereas volatile fatty acid concentration increased with age. Overall $\mathrm{pH}$ had a cubic trend with SS lower than that of PS and MS. Molar proportion of acetate decreased with age whereas propionate proportion increased. Overall molar proportions of volatile fatty acids were not affected by diet. Fecal $\mathrm{X}_{\mathrm{gm}}$ was not different in spite of changes in diet particle size and rumen digesta of PS being greater than SS, MS, and LS at slaughter. Fecal $\mathrm{pH}$ and starch concentration were not affected by diet; however, $\mathrm{pH}$ decreased whereas starch content increased with age. Weight of stomach compartments, rumen papillae length and width, and rumen wall thickness did not differ between diets. Omasum weight as a

Received May 29, 2015.

Accepted August 24, 2015.

${ }^{1}$ This research was a component of NC-2042; Management Systems to Improve the Economic and Environmental Sustainability of Dairy Enterprises.

${ }^{2}$ Corresponding author: ajh@psu.edu
\end{abstract}

percentage of body weight at harvest linearly decreased as straw particle size increased. Under the conditions of this study, modifying straw particle length in starter grain resulted in minimal rumen fermentation parameter changes and no changes in rumen development. Rumen $\mathrm{pH}$ and fermentation changes with age were likely effects of increasing starter intake.

Key words: calf, rumen fermentation, forage, straw, particle size

\section{INTRODUCTION}

The physical development of rumen papillae and the capacity for absorption and metabolism of digestion end products by the rumen wall in the young calf are stimulated by VFA produced by rumen fermentation rather than feed coarseness (Flatt et al., 1958). Propionate and butyrate are the most important VFA for papillae growth (Tamate et al., 1962) and are products of the fermentation of grains. For this reason, grains (starches) are the most important component in a young calf's diet for inducing rumen development. Grains are frequently fed in a pelleted form with fine particle size because forming a firm pellet requires fine grinding of grains (Davis and Drackley, 1998), and when pelleted concentrates are the only solid feed available papillae have been shown to become parakeratotic, exhibiting abnormal growth and compaction with fine feed particles (McGavin and Morrill, 1976). The small particle size of many all-ground diets does not provide the necessary abrasiveness to remove the keratin layer and compacted feed from the developing rumen papillae. Greenwood et al. (1997) observed that keratinization of papillae was inversely related to the diet's abrasiveness when using a finely ground, pelletized diet.

Particle size of starter also has been shown to affect rumen fermentation. Diets with greater particle size resulted in higher rumen pH (Greenwood et al., 1997; Beharka et al., 1998), possibly due to an increase in the time calves spend ruminating as particle size increases (Hodgson, 1971), thereby affecting saliva production, which increases rumen buffering (Krause and Oetzel, 
2006). Increasing starter particle size by feeding it in a coarse mash form versus ground and pelleted reduced the age at which calves started ruminating and increased the time spent ruminating (Porter et al., 2007).

Two common ways to increase the particle size of solid feed for the young calf are to feed a mix of whole grains or less processed grains and a supplemental pellet or to include forage in the ration. Studies by Beharka et al. (1998) and Greenwood et al. (1997) investigated the effects of increasing particle size without changing diet composition, at controlled DMI, and avoiding bedding consumption, at inclusions of $25 \%$ alfalfa hay (Beharka et al., 1998) and $15 \%$ bromegrass hay (Greenwood et al., 1997). Forage levels of 15 to $25 \%$ may be too high when feeding low-quality forage, as reports have shown that when calves have ad libitum access to straw consumption is about $4 \%$ of solid feed intake (Thomas and Hinks, 1982; Castells et al., 2013). Moreover, Fokkink et al. (2011) observed that straw intake decreased from about $4 \%$ of solid feed intake through $5 \mathrm{wk}$ of age to about $1 \%$ from 5 to $8 \mathrm{wk}$ in calves that had no access to consume bedding. Hence, high inclusion rates of forage $(>10 \%)$ in the preweaned calf diet reduce the proportion of grains in the ration and may reduce starter intake, possibly lowering the production of VFA in the rumen which may slow down the development of the rumen epithelium. Stobo et al. (1966) observed that as concentrate intake increased (by increasing its allowance), papillae tended to be larger. However, other researchers have suggested that forage allowance may actually increase total DMI and that it could benefit rumen development (Khan et al., 2011; Castells et al., 2013). A small amount of forage with particle size $>1.18 \mathrm{~mm}$, which is the threshold particle size for particles leaving the rumen in adult cattle and sheep (Maulfair et al., 2011), may satisfy the calf's requirement for abrasiveness to avoid the buildup of keratin in the rumen epithelium and maintain a more stable rumen fermentation. When the particle size of starter was evaluated in calves fed no hay and without access to consume bedding materials up to $8 \mathrm{wk}$, it was determined that over $50 \%$ of particles should be larger than $1.19 \mathrm{~mm}$ to ensure adequate intake, proper rumen fermentation (Warner et al., 1973), and prevent physiological abnormalities (Porter et al., 2007).

Due to these findings, our study aimed to evaluate the inclusion of a small amount of straw (5\%) with different particle sizes in calf starter on rumen $\mathrm{pH}$, rumen fermentation, and development of the digestive system. A secondary objective was to observe rumen fermentation at an early age. We hypothesized that greater particle size of straw in the starter would enhance rumen development by providing abrasiveness to the rumen epithelium and a more stable rumen fermentation

\section{MATERIALS AND METHODS}

Protocols for this study were approved by The Pennsylvania State University Institutional Animal Care and Use Committee under IACUC \# 41845. Two studies were done as part of this experimental protocol.

In trial 1 , Holstein bull calves $(\mathrm{n}=20)$ purchased from a single commercial herd were removed from their dam after birth, weighed, and fed 3.6 L of colostrum within an hour of birth. Calves were then transported for $20 \mathrm{~min}$ to the research facility where they were fed an additional $1.8 \mathrm{~L}$ of colostrum 6 to $8 \mathrm{~h}$ after the first feeding. Housing consisted of individual pens $2.1 \times$ $1.6 \mathrm{~m}$ inside a mechanically ventilated, heated facility; bedding (wood shavings) was completely covered with landscape fabric to avoid any consumption of bedding, thus the only solid feed available came from treatment diets. Water was offered free choice, and a commercial milk replacer powder containing $20 \% \mathrm{CP}$ and $20 \%$ fat (US Feeds, Eldora, IA) and reconstituted to $13 \%$ DM was fed at $12 \%$ of birth BW divided in 2 equal feedings per day. Decoquinate (Deccox-M; Alpharma, Bridgewater, NJ) was added to milk replacer to feed at $0.5 \mathrm{mg} / \mathrm{kg}$ of BW. At 7 wk of age, milk replacer allowance was cut to $6 \%$ of birth BW for 1 wk before weaning. Calves were randomly assigned based on date and birth BW to 1 of 4 treatments differing in geometric mean particle length $\left(\mathbf{X}_{\mathrm{gm}}\right)$ of straw comprising $5 \%$ of starter DM. Straw was provided within the pellet (PS; $0.82 \mathrm{~mm} \mathrm{X}_{\mathrm{gm}}$ ) or mixed with the pellet at $\mathrm{X}_{\mathrm{gm}}$ of $3.04 \mathrm{~mm}(\mathbf{S S}), 7.10 \mathrm{~mm}(\mathbf{M S})$ or $12.7 \mathrm{~mm}(\mathbf{L S})$ at time of feeding. Calves (3/treatment) were ruminally fistulated with $28-\mathrm{mm}$ (i.d.) rubber cannulas by wk 2 of life in a similar manner as Lesmeister and Heinrichs (2004). Pellets and straw for treatments SS, MS, and LS were proportionally mixed for each calf daily. The 2 pellets were manufactured with all ingredients coming from the same batch and in enough quantity for both trials. The pellets were made under ambient conditions without added steam. The meal was conditioned for approximately $20 \mathrm{~s}$ with $75^{\circ} \mathrm{C}$ forced, ambient air and pelleted at $200 \mathrm{kPa}$ at $75^{\circ} \mathrm{C}$. Calf starter was fed once daily at $2000 \mathrm{~h}$ after milk replacer feeding; the amount of starter offered was adjusted with age and was based on average intakes of calves fed similar milk replacer diets. To equalize intake, calves were fed a fixed amount of starter that changed with age and was determined by previous experiences with calves on similar milk replacer diets and by the voluntary consumption of most calves; orts were fed through the cannula in cannulated calves, except during the last week of the experiment. The different lengths of straw were obtained by chopping wheat straw and sieving it in the ASABE (2007) particle size separator equipped with 5 screens (nominal 
size opening $19,12.7,6.3,3.96$, and $1.17 \mathrm{~mm}$ for 1 to 5 respectively) and a bottom pan, particles in the bottom pan were used for PS, and particles retained on screens 5,4 , and 3 for treatments SS, MS, and LS respectively. Calf health was monitored twice daily, and sick calves were treated per veterinary recommendation.

Rumen contents were sampled $1 \mathrm{~d} /$ wk starting $1 \mathrm{wk}$ after starter was offered ( 3 wk of age) at $-8,-4,0,2$, 4,8 , and $12 \mathrm{~h}$ after starter feeding. Contents (about 40 $\mathrm{mL}$ ) were strained through 2 layers of cheese cloth, and $\mathrm{pH}$ of the fluid fraction was immediately determined with a hand-held pH meter (pHTestr 10, Eutech Instruments, Vernon Hills, IL). Rumen fluid $(5 \mathrm{~mL})$ was then placed into tubes containing $1 \mathrm{~mL}$ of $25 \%$ metaphosphoric acid and $1 \mathrm{~mL}$ of $6 \%$ 2-ethyl butyric acid (internal standard) and stored at $-20^{\circ} \mathrm{C}$ until analyzed for VFA and $\mathrm{NH}_{3}$. After thawing, rumen fluid was centrifuged 3 times at $4,000 \times g$ for $30 \mathrm{~min}$ at $4^{\circ} \mathrm{C}$ to obtain a clear supernatant, which was analyzed for $\mathrm{NH}_{3}$ according to Chaney and Marbach (1962). Supernatant was filtered through a $0.45-\mu \mathrm{m}$ polypropylene membrane before being analyzed for VFA molar concentration by GC (Yang and Varga, 1989).

A xylose absorption test was conducted to assess small intestine absorption capacity when grain feeding began and weekly thereafter. D-Xylose (Alfa Aesar, Ward Hill, MA) was administered in the morning milk replacer at $0.5 \mathrm{~g} / \mathrm{kg}$ of $\mathrm{BW}$. Blood samples were taken before and $4 \mathrm{~h}$ after xylose administration via jugular venipuncture into evacuated tubes sprayed with anticoagulant $\left(\mathrm{K}_{2}\right.$ EDTA; Becton, Dickinson and Company, Franklin Lakes, NJ). Blood was centrifuged at 3,600 $\times g$ for 15 min at $4^{\circ} \mathrm{C}$ and plasma was stored at $-20^{\circ} \mathrm{C}$ until analysis. Xylose concentration in plasma was analyzed as described by Merritt and Duelly (1983); absorption was calculated by the difference before and after xylose administration.

At 9 wk of age (6 wk of grain feeding) calves were killed via captive bolt stunning and exsanguination. Reticulorumens, omasums, and abomasums were collected, emptied, rinsed with cold water, drained of excess water, dissected, and weighed. Livers and spleens were collected, rinsed with cold water, drained of excess water, and weighed. Reticulorumen contents were strained through 2 layers of cheese cloth; the solid fraction was stored at $-20^{\circ} \mathrm{C}$ until analyzed for particle length.

In trial 2 , calves $(\mathrm{n}=25)$ from the same source received first and second colostrum feedings before transported to the same facility as trial 1 . At arrival, calves were dosed with a capsule containing bovine coronavirus-Escherichia coli antibody (First Defense; Immucell, Portland, ME) and $250 \mathrm{mg}$ of oxytetracycline (Durvet,
Blue Springs, MO) administered orally, $5 \mathrm{~mL}$ of fortified vitamin B complex (Agrilabs, St. Joseph, MO) administered subcutaneously, and $3 \mathrm{~mL}$ of florfenicol (Nuflor; Intervet, Summit, NJ) administered intramuscularly. Oxytetracycline $(250 \mathrm{mg})$ was administered every 12 $\mathrm{h}$ until $48 \mathrm{~h}$ from the first dose, and a second dose of florfenicol was administered $48 \mathrm{~h}$ after the first dose. Starters were fed after morning milk replacer feeding starting at 6 to $8 \mathrm{~d}$ of life; starters and straw were the same as in trial 1. Medicated $(158 \mathrm{mg} / \mathrm{kg}$ of lasalocid; Alpharma Inc., Fort Lee, NJ) milk replacer powder containing 20\% CP and 20\% fat (Provimi North America, Brookville, $\mathrm{OH}$ ) was reconstituted and fed in a similar manner and rate as in trial 1 , evening milk replacer feeding was withheld to calves that were low on starter intake and to all calves 2 wk before slaughter. Calves were not fistulated and feces were not collected in this trial; slaughter was done as in trial 1 , at 6 wk after starter was first offered ( 7 wk of age).

Samples of manufactured pellets were collected from every second bag $(22.7 \mathrm{~kg})$ at the time of manufacturing and composited. Pellet samples were analyzed (AOAC International, 2000) for DM (oven method 930.15), ash (oven method 942.05), CP (Kjeldahl method 988.05), fat (diethyl ether extraction method 2003.05), and Ca and $\mathrm{P}$ (dry ashing, acid digestion, analysis by inductively coupled plasma spectroscopy; method 985.01). Additionally, NDF with ash concentration by the procedure of Van Soest et al. (1991) without sodium sulfite or $\alpha$-amylase, ADF with ash concentration (Robertson and Van Soest, 1981), and acid-detergent insoluble lignin (Goering and Van Soest, 1970) were quantified. A portion of fecal samples was dried in a forced-air oven at $55^{\circ} \mathrm{C}$ for $72 \mathrm{~h}$ to determine DM and starch content. Feeds and feces were gelatinized with sodium hydroxide for starch concentration analysis by the Karkalas (1985) enzymatic method.

Feces were collected from the landscape fabric over a 22 -h period at the same time of rumen sampling and $2 \mathrm{~h}$ after the last rumen sampling; samples were stored at $-20^{\circ} \mathrm{C}$ for later analysis. Particle size distribution of feces and the solid fraction of reticulorumen contents were analyzed via the wet-sieving technique of Maulfair and Heinrichs (2010), using screen sizes 0.15, 0.425, $0.60,0.85,1.0,1.18$, and $3.35 \mathrm{~mm}$ (VWR, Arlington Heights, IL). Starters were submerged in hot water for $10 \mathrm{~min}$ before sieving. The fraction that passed through the $0.15-\mathrm{mm}$ screen was considered soluble. Data were analyzed considering percentage of DM of each particle fraction retained on screens $\geq 0.15 \mathrm{~mm}$ (retained) and including the soluble fraction (total). Geometric mean particle length $\left(\mathrm{X}_{\mathrm{gm}}\right)$ was calculated (ASABE, 2007) with particles retained on the top screen assumed to be 
$4.7 \mathrm{~mm}$ long (square hole diagonal of top screen). This was followed by reticulorumen dissection and measurement of rumen papillae and wall thickness Lesmeister et al. (2004; five 1-cm ${ }^{2}$ samples collected from each of 9 areas), with 8 papillae measured per sample (40/area) and rumen wall thickness measured twice per sample (10/area).

Data were analyzed using the MIXED procedure in SAS (Version 9.4; SAS Institute Inc., Cary, NC) as a completely randomized design; a completely randomized block design with trial as block was used when variables from both trials were analyzed together (rumen contents particle size, Table 5; xylose absorption and rumen development, Table 7). Calf within treatment was a random effect used to test the fixed effect of treatment, trial was a fixed effect, and its interaction with treatment was tested in the model. Fixed effect of time and its interactions with other fixed effects were included in the model when multiple observations occurred between weeks and within sampling day. Repeated measures using autoregressive (1) covariance structure were used for intake, xylose, and fecal particle size data. Heterogeneous compound symmetry covariance structure was used for fecal $\mathrm{pH}$ and starch. Goodness of fit criteria were used to select covariance structures for these variables. Packed cell volume (\%) was used as a covariate for xylose. Spatial (power) covariance structure $[\mathrm{SP}(\mathrm{POW})]$ was used for rumen fermentation data because of unequally spaced sampling points. Linear and quadratic contrasts for diets and time after grain feeding between weeks and within sampling day were tested using the CONTRAST statement. Least squares means are presented in tables, and evidence for statistical significance was declared at $P<$ 0.05 with trends at $P<0.10$.

\section{RESULTS AND DISCUSSION}

In trial 1, 3 calves died for reasons unrelated to dietary treatments, before they were started on experimental diets. Ingredient composition of starter (Table 1) differed only in the particle size of straw, nutrient composition of PS versus SS, MS, and LS was similar when straw chemical analysis was proportionally added to the pellet used to mix those diets. The straw put in the pellet in PS diet did not affect its $\mathrm{X}_{\mathrm{gm}}$, as the $\mathrm{X}_{\mathrm{gm}}$ of PS and the pellet used for SS, MS, and LS were similar. The proportion of particles $>1.18 \mathrm{~mm}$ in the PS diet and the pellet used for SS, MS, and LS was lower than the recommended particle size (50\% of particles $>1.19$ $\mathrm{mm}$ ) for calves fed starter with no forage and without access to consume bedding, to ensure adequate intake, proper rumen fermentation (Warner et al., 1973), pre-
Table 1. Ingredient and chemical composition and particle size of starters containing 5\% straw differing in particle size either in the pellet (PS) or mixed with the pellet

\begin{tabular}{|c|c|c|}
\hline Item & PS & Pellet $^{1}$ \\
\hline \multicolumn{3}{|c|}{ Ingredient composition, $\%$ of DM } \\
\hline Ground corn & 42.57 & 44.79 \\
\hline Wheat middlings & 25.00 & 26.32 \\
\hline Soybean meal, $48 \% \mathrm{CP}$ & 20.94 & 22.05 \\
\hline Wheat straw ${ }^{2}$ & 5.00 & - \\
\hline Cane molasses & 3.00 & 3.15 \\
\hline Calcium carbonate & 1.24 & 1.30 \\
\hline Premix $^{3}$ & 0.75 & 0.79 \\
\hline Salt & 0.75 & 0.80 \\
\hline Decoquinate, $6 \%$ & 0.50 & 0.53 \\
\hline Monocalcium phosphate & 0.26 & 0.28 \\
\hline \multicolumn{3}{|c|}{ Chemical composition, \% of DM } \\
\hline $\mathrm{DM}$ & 88.04 & 86.44 \\
\hline $\mathrm{CP}$ & 17.69 & 19.98 \\
\hline Starch & 37.06 & 39.50 \\
\hline Crude fat & 3.79 & 3.73 \\
\hline $\mathrm{ADF}$ & 8.39 & 6.57 \\
\hline NDF & 15.22 & 12.43 \\
\hline Ash & 6.13 & 6.17 \\
\hline $\mathrm{Ca}$ & 0.90 & 1.06 \\
\hline $\mathrm{P}$ & 0.55 & 0.57 \\
\hline \multicolumn{3}{|l|}{ Particle size } \\
\hline $\mathrm{X}_{\mathrm{gm}}$, retained $^{4}$ & 1.19 & 1.19 \\
\hline $\mathrm{S}_{\mathrm{gm}}$, retained $^{4}$ & 1.17 & 1.16 \\
\hline $\mathrm{X}_{\mathrm{gm}}$, total $^{5}$ & 0.61 & 0.60 \\
\hline $\mathrm{S}_{\mathrm{gm}}$, total $^{5}$ & 1.53 & 1.54 \\
\hline$\%>1.18 \mathrm{~mm}^{6}$ & 36.06 & 37.34 \\
\hline
\end{tabular}

${ }^{1}$ Pellet used for diets short, medium, and long straw.

${ }^{2}$ Straw contained (\% DM): $3.9 \mathrm{CP}, 53.7 \mathrm{ADF}, 78.3 \mathrm{NDF}$, and 8.28 lignin. Geometric mean particle length was $0.82,3.04,7.10$, and 12.7 $\mathrm{mm}$ for PS, short, medium, and long straw, respectively.

${ }^{3}$ The premix contained (per $\mathrm{kg}$ ): $160 \mathrm{~g}$ of $\mathrm{Cu}, 0.13 \mathrm{~g}$ of $\mathrm{Co}, 9.40 \mathrm{~g}$ of $\mathrm{Fe}, 0.14 \mathrm{~g}$ of I, $5.4 \mathrm{~g}$ of Mn, $0.04 \mathrm{~g}$ of Se, $6.70 \mathrm{~g}$ of $\mathrm{Zn}, 1,800 \mathrm{IU}$ of vitamin A, $600 \mathrm{IU}$ of vitamin D, $16 \mathrm{IU}$ of vitamin $\mathrm{E}, 0.01 \mathrm{~g}$ of biotin, $2.93 \mathrm{~g}$ of cobalamin, $0.04 \mathrm{~g}$ of folic acid, $1.77 \mathrm{~g}$ of niacin, $1.32 \mathrm{~g}$ of pantothenic acid, $0.24 \mathrm{~g}$ of pyridoxine, $0.30 \mathrm{~g}$ of riboflavin, $0.29 \mathrm{~g}$ of thiamin (Provimi North America, Brookville, OH).

${ }^{4}$ Geometric mean $\left(\mathrm{X}_{\mathrm{gm}}\right)$ and standard deviation $\left(\mathrm{S}_{\mathrm{gm}}\right)$ of particle length as calculated by ASABE (2007) using data from screens $\geq 0.15 \mathrm{~mm}$. Particles retained on the top screen were assumed to be $4.7 \mathrm{~mm}$ long. ${ }^{5}$ Geometric mean $\left(\mathrm{X}_{\mathrm{gm}}\right)$ and standard deviation $\left(\mathrm{S}_{\mathrm{gm}}\right)$ of particle length as calculated by ASABE (2007) using data from all particle fractions. Particles retained on the top screen were assumed to be $4.7 \mathrm{~mm}$ long. ${ }^{6}$ Cumulative proportion of retained particles over a $1.18-\mathrm{mm}$ sieve.

vent physiological abnormalities, and initiate rumination (Porter et al., 2007); hence, the effect of straw particle size would have been enhanced. Table 2 shows BW of calves in each trial, which was similar across treatments at birth and at slaughter. In all results, week refers to time after starter was available and not chronological age when not specified.

Mean starter intake (including orts put through the cannula in 12 cannulated calves in trial 1) was similar across treatments and increased with time by design (Figure 1; Table 3). Most days noncannulated calves ate their full feed allotment, and no orts were collected from noncannulated calves except on the last day of 
Table 2. Description of calves fed starters containing 5\% straw differing in particle size either in the pellet (PS) or mixed with the pellet: short (SS), medium (MS), and long straw (LS)

\begin{tabular}{lcccccc}
\hline & \multicolumn{7}{c}{ Diet } & & \\
\cline { 2 - 5 } Item & PS & SS & MS & LS & SEM & $P$-value \\
\hline Calves, no. & 4 & 4 & 4 & 5 & - & - \\
$\quad$ Trial 1 & 7 & 6 & 6 & 6 & - & - \\
Trial 2 & 43.5 & 43.4 & 44.5 & 43.9 & 1.2 & 0.93 \\
BW at birth, $\mathrm{kg}$ & 64.7 & 65.2 & 63.4 & 67.2 & 2.5 & 0.72 \\
BW at slaughter, ${ }^{1} \mathrm{~kg}$ & &
\end{tabular}

${ }^{1} \mathrm{BW}$ of calves at slaughter was heavier in trial 2 than in trial 1 ( 69.0 vs. $\left.61.3 \mathrm{~kg} ; P<0.01\right)$.

the trials. A diet by week interaction was detected in trial 1 for wk 6, where PS and MS intake was lower than SS and LS. Most of the difference comes from orts of the last starter feeding before slaughter; however, it was also influenced by some fistulated calves' reduced intake, possibly due to acidosis, in wk 6 ( $\mathrm{PS}=2$, MS $=2, \mathrm{SS}=1)$. Starter intake was greater in trial 1 when compared with trial 2 (3,559 vs. 1,928 g/wk). Age of calves when starter was available was greater in trial 1 ( 3 vs. 1 wk of age), calves in trial 1 were completely weaned during wk 6 , and the time between trials may have affected the palatability of pellets. Milk replacer evening feeding was withheld in calves not eating at least $50 \%$ of their daily starter allowance, the proportion of skipped meals (fixed for uneven animal number) was not evenly distributed among treatments (118 total skipped meals; PS $=19 \%, \mathrm{SS}=15 \%, \mathrm{MS}=43 \%$, LS $=$ $23 \%$ ); however, it did not affect MR intake across diets,

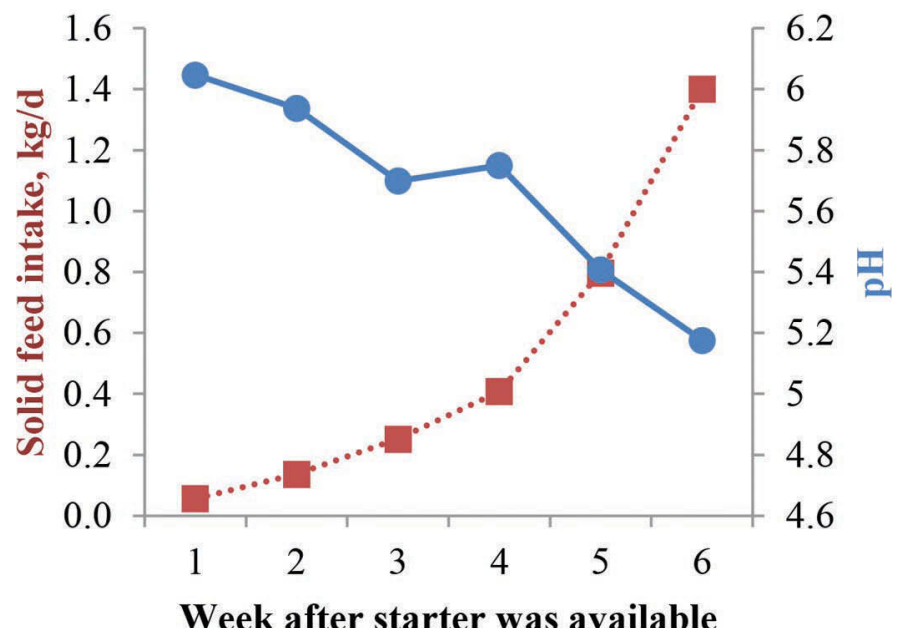

Figure 1. Mean solid feed intake (17 calves, $\mathbf{\square}$; SEM = 748) and rumen $\mathrm{pH}(12$ calves, $\bullet$ : SEM $=0.06)$ from 1 to 6 wk after starter was available for calves fed starter containing $5 \%$ straw differing in particle size either in the pellet (PS) or mixed with the pellet: short (SS), medium (MS), and long straw (LS) in trial 1. Color version available online. possibly because the number of skipped meals was only about $7 \%$ of total offered meals.

\section{Rumen Fermentation and Digesta Particle Size}

Rumen fermentation data comes from 12 fistulated calves (3/treatment) in trial 1 and is presented in Table 4. Rumen $\mathrm{pH}$ decreased linearly with age (Figure 1), and the overall value for SS was lower than that of PS and MS (5.81 PS; 5.50 SS; 5.75 MS; 5.62 LS; cubic effect, $P<0.05)$. This cubic effect of diet is different from our hypothesis, as we expected $\mathrm{pH}$ to increase linearly as particle size increased. Possibly, intake in wk 6 influenced $\mathrm{pH}$ and is responsible for the cubic effect, as PS and MS had higher intakes in wk 6. Beharka et al. (1998) observed an increase in rumen $\mathrm{pH}$ for larger particle size when comparing ground versus unground diets. Particle size differences in their study were larger, as forage constituted $25 \%$ of the starter and grains were also ground or unground; these may be reasons why particle size had a greater effect on rumen $\mathrm{pH}$. Greenwood et al. (1997) also observed higher rumen $\mathrm{pH}$ with diets greater in particle size when forage constituted $15 \%$ of starter. The decline in $\mathrm{pH}$ with age is consistent with Suarez-Mena et al. (2015), where calves were fed grain for $4 \mathrm{wk}$. When calves were studied for a longer period of time, Anderson et al. (1987) and Beharka et al. (1998) reported a quadratic response of $\mathrm{pH}$ to age, but it declined consistently for about 6 wk. As shown in Figure 1, the decline in $\mathrm{pH}$ with age is responsive to solid feed intake increasing by wk. Figure 2 illustrates $\mathrm{pH}$ variation over time after feeding grain; a nadir was reached at approximately $2 \mathrm{~h}$ postfeeding for wh 2 and 6 , and at $4 \mathrm{~h}$ for wk 1, 3, 4, and 5 . The postprandial $\mathrm{pH}$ variation is comparable to what we observed in a previous study with similar management (Suarez-Mena et al., 2015). Anderson et al. (1987) observed lowest $\mathrm{pH}$ values 1 to $3 \mathrm{~h}$ postfeeding and a faster recovery to prefeeding values than in the present study; at its nadir average $\mathrm{pH}$ was over 5 , which was higher than what we observed in the present study. The $\mathrm{pH}$ values 
Table 3. Intake of calves fed starters containing 5\% straw differing in particle size either in the pellet (PS) or mixed with the pellet: short (SS), medium (MS), and long straw (LS)

\begin{tabular}{|c|c|c|c|c|c|c|c|c|c|c|}
\hline Item & & & & & & & $\begin{array}{l}\text { Highest } \\
\text { SEM }\end{array}$ & \multicolumn{3}{|c|}{$P$-value } \\
\hline \multicolumn{11}{|l|}{ Trial $1^{2}$} \\
\hline $\mathrm{MRI}^{3} \mathrm{~g} / \mathrm{wk}$ & 4,813 & 4,813 & 4,813 & 4,813 & 2,301 & 0 & 77 & 0.86 & $<0.01$ & $<0.01$ \\
\hline \multicolumn{11}{|l|}{ Starter intake, ${ }^{4} \mathrm{~g} / \mathrm{wk}$} \\
\hline MS & 405 & 1,005 & 1,776 & 2,844 & 5,021 & $8,202^{\mathrm{a}}$ & 748 & - & - & - \\
\hline LS & 405 & 1,005 & 1,820 & 2,800 & 5,366 & $12,104^{\mathrm{b}}$ & 669 & - & - & - \\
\hline \multicolumn{11}{|l|}{ Trial 2} \\
\hline MRI, g/wk ${ }^{3}$ & 4,761 & 4,706 & 4,348 & 3,683 & 2,381 & 1,957 & 114 & 0.56 & $<0.01$ & $<0.01$ \\
\hline \multicolumn{11}{|l|}{ Starter intake, ${ }^{4} \mathrm{~g} / \mathrm{wk}$} \\
\hline PS & 310 & 895 & 1,598 & 2,158 & 3,375 & 4,031 & 319 & 0.69 & $<0.01$ & 0.04 \\
\hline SS & 322 & 962 & 1,640 & 2,157 & 3,195 & 3,703 & 344 & - & - & - \\
\hline
\end{tabular}

\footnotetext{
${ }^{\mathrm{a}, \mathrm{b}}$ Different superscripts indicate diet $\times$ week interaction differences $(P<0.05)$.

${ }^{1}$ From the time starter was fed.

${ }^{2}$ Includes the feed that was put through the cannula for the 12 fistulated calves in trial 1.

${ }^{3}$ Milk replacer powder intake, as fed.

${ }^{4}$ Starter grain with $5 \%$ straw, as fed.
}

observed by Laarman et al. (2012) are also higher than in our study; however, calves had ad libitum access to forage and were older. Although not specified, calves in Anderson et al. (1987) may have also had access to bedding, as they were housed in calf hutches. At the end of wk 5, fistulated calves $(\mathrm{n}=5)$ showed clinical signs of acidosis: anorexia, lethargy, diarrhea (Owens et al., 1998), and abdominal discomfort. Differences in $\mathrm{pH}$ were analyzed for calves with acidosis symptoms versus calves not showing these symptoms, and it was determined that, on wk 5 , pH of calves showing signs of acidosis declined up to $8 \mathrm{~h}$ after feeding versus $2 \mathrm{~h}$ after feeding for calves not showing acidosis symptoms (Figure 3). As none of the nonfistulated calves in either trial showed these symptoms at that age, it is likely that our attempt to equalize intake by feeding orts through the cannula created acidosis in these calves. The 5 calves showing these symptoms were often fed through the cannula, and the amounts that were fed through the cannula as calves aged was likely too large and overwhelmed the ability of these calves to maintain $\mathrm{pH}$. Furthermore, starter introduced through the cannula was not chewed, so it did not contribute to the flow of saliva with its buffering compounds to the rumen. Potential carryover effects of low $\mathrm{pH}$ on performance and health cannot be determined from our study.

Total rumen VFA concentration did not differ by diet, but a diet by week interaction was observed where PS had lower concentration than SS and LS in wk 5 and lower than SS in wk 6 . As with $\mathrm{pH}$, these observations may be related to solid feed intake differences in wk 6. Greater rumen VFA concentration with smaller particle size was reported by Coverdale et al. (2004), and Beharka et al. (1998), although the latter was a numerical difference only $(P=0.12)$. In both studies, calves fed smaller particle size rations had increased keratinization of the rumen papillae, which has been shown to reduce the amount of VFA absorption (Hinders and Owen, 1965). In our previous study (Suarez-Mena et al., 2015) and in the Greenwood et al. (1997) study, particle size of diets did not affect VFA concentration. Total concentration of VFA in the rumen increased with age as has been reported by earlier studies (Greenwood et al., 1997; Beharka et al., 1998; Coverdale et al., 2004). In our previous study (Suarez-Mena et al., 2015), rumen VFA concentration increased with age in a quadratic trend with a small decrease at wk 4, which is somewhat similar to the current study where a plateau was observed between wk 3 and 5 and then an increase at wk 6 . The decrease observed in Suarez-Mena et al. (2015) and plateau in the current study are likely an effect of greater VFA absorption, because intake increased with time and it is assumed VFA production increases with greater intake. Total rumen VFA postprandial variation (Figure 4), was consistent with previous reports (Anderson et al., 1987; Quigley et al., 1992; Suarez-Mena et al., 2015), with peaks between 2 and $4 \mathrm{~h}$ after feeding when $\mathrm{pH}$ was at its lowest. Molar proportions of individual VFA were not affected by diet; interactions between week 
Table 4. Rumen fermentation of 12 calves fed starters containing 5\% straw differing in particle size either in the pellet (PS) or mixed with the pellet: short (SS), medium (MS), and long straw (LS) in trial 1

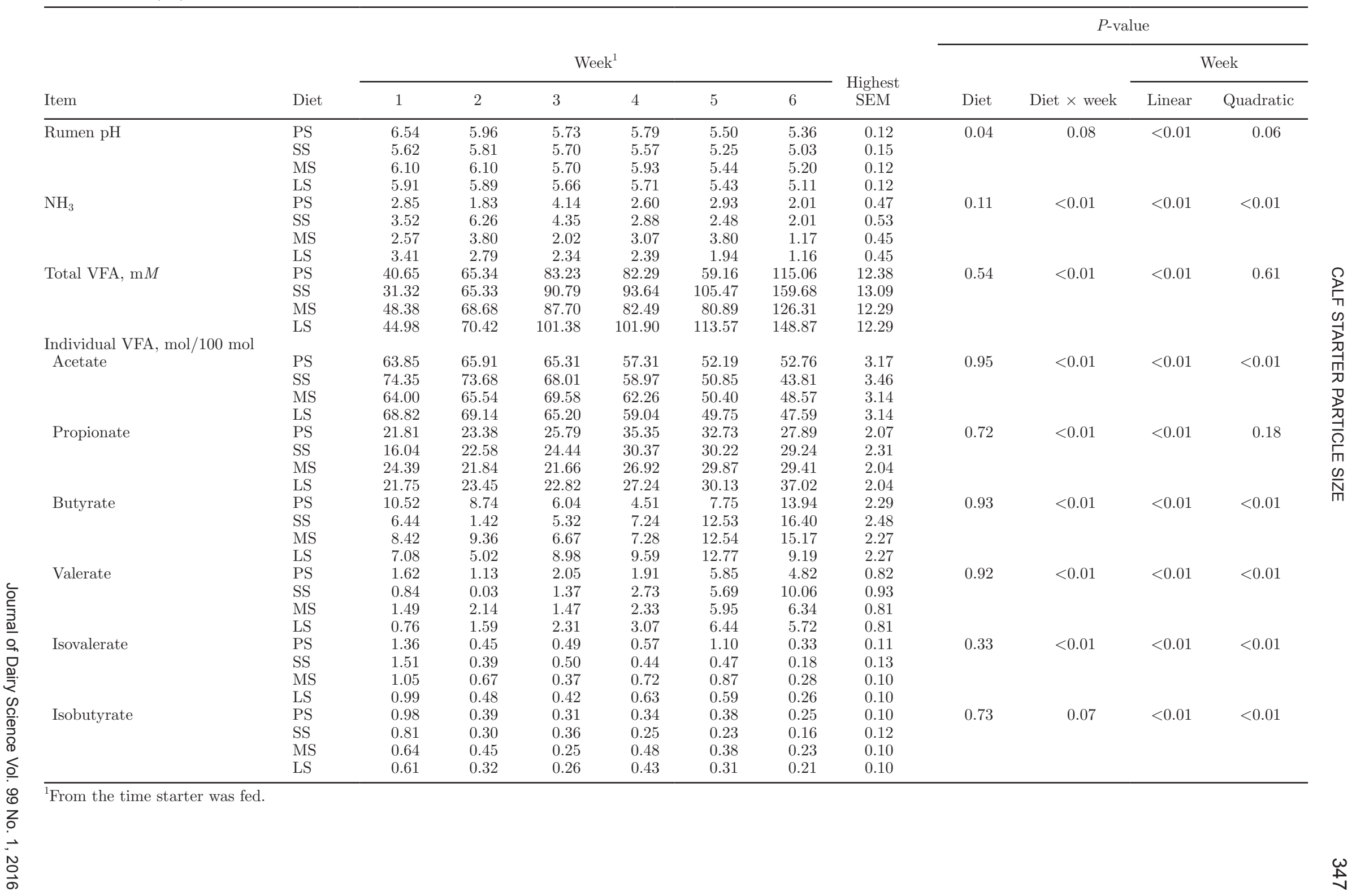




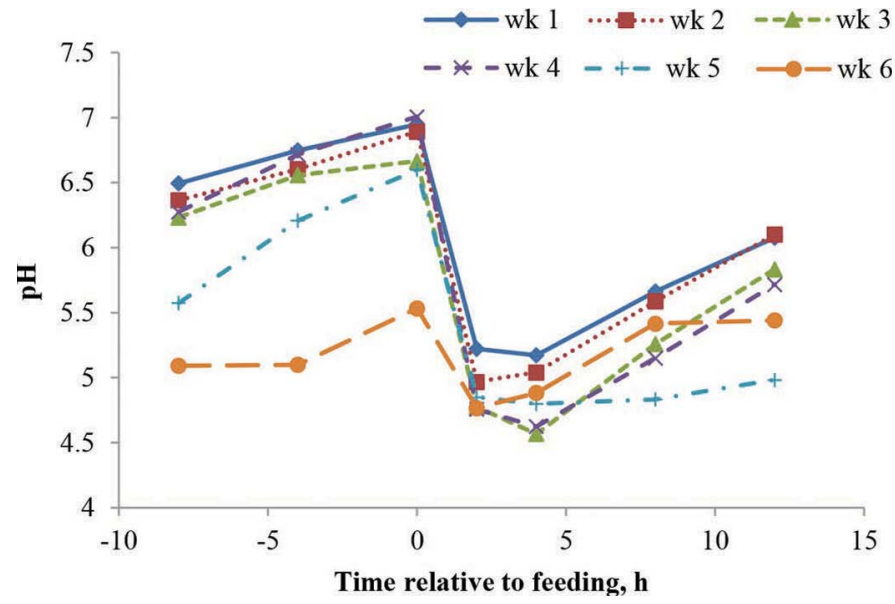

Figure 2. Mean rumen $\mathrm{pH}$ variation at $-8,-4,0,2,4,8$, and 12 $\mathrm{h}$ relative to feeding from 1 to $6 \mathrm{wk}$ after starter was available for 12 calves fed starter containing 5\% straw differing in particle size either in the pellet (PS) or mixed with the pellet: short (SS), medium (MS), and long straw (LS) in trial 1. Linear effect for week, $P<0.01$; cubic effect for time relative to feeding, $P<0.01(\mathrm{SEM}=0.15)$. Color version available online.

and diet, although statistically significant, did not seem to follow a biologically sound trend and thus are not discussed. Molar proportion of acetate decreased as calves aged, whereas proportions of propionate, butyrate, and valerate increased, similar to results obtained by others (Anderson et al., 1987; Beharka et al., 1998); however, butyrate proportion decreased at 12 wk of age in the Anderson et al. (1987) study. Interestingly, in our previous study (Suarez-Mena et al., 2015), molar proportions of acetate increased with age whereas propionate and butyrate decreased; these conflicting results

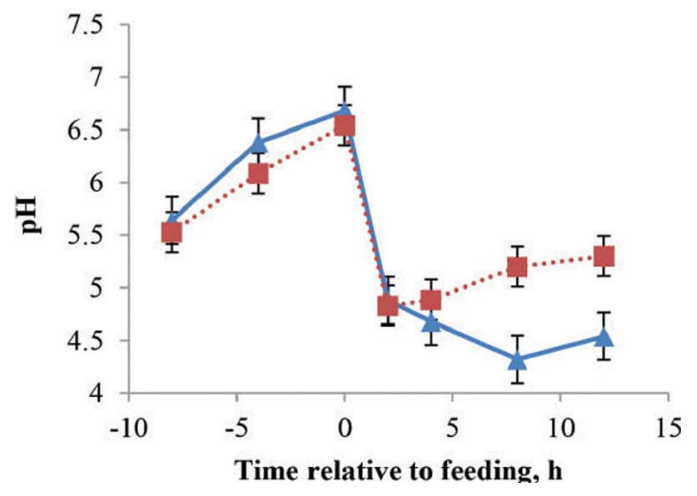

Figure 3. Mean rumen $\mathrm{pH}$ variation at $-8,-4,0,2,4,8$, and 12 $\mathrm{h}$ relative to feeding $5 \mathrm{wk}$ after solid feed was available for 12 calves that showed (5 calves; $\mathbf{\Delta}$ ) or did not show (7 calves; $\mathbf{0}$ ) acidosis symptoms in trial 1 . The probability for the 3 -way interaction for acidosis symptoms versus not, week, and time from feeding was $P<0.01$. Differences between groups at 8 and $12 \mathrm{~h}$ after feeding were significant, $P<0.05$. Color version available online.

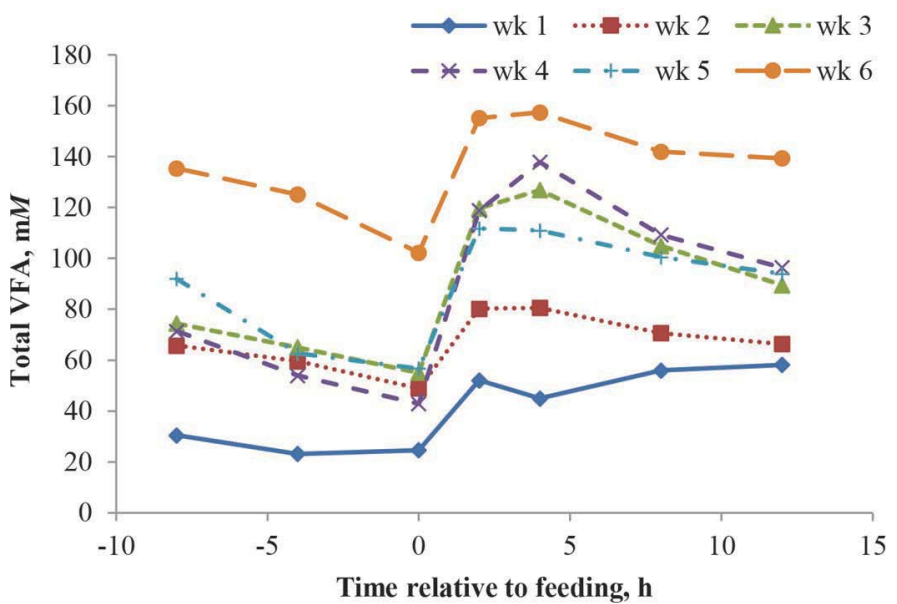

Figure 4. Mean total VFA variation at $-8,-4,0,2,4,8$, and 12 $\mathrm{h}$ relative to feeding from 1 to $6 \mathrm{wk}$ after starter was available for 12 calves fed starter containing $5 \%$ straw differing in particle size either in the pellet (PS) or mixed with the pellet: short (SS), medium (MS), and long straw (LS) in trial 1 . Linear effect for week, $P<0.01$; cubic effect for time relative to feeding, $P<0.01(\mathrm{SEM}=10.7)$. Color version available online.

may be related to differences on diets composition and rumen $\mathrm{pH}$. Isoacids molar proportion was low and decreased with calf age, as previously reported (Anderson et al., 1987; Beharka et al., 1998; Suarez-Mena et al., 2015). Rumen $\mathrm{NH}_{3}$ was not different between dietary treatments and decreased as calves aged; a decrease with age is consistent with the literature and is likely a result of increased use by rumen microbial population (Anderson et al., 1987; Beharka et al., 1998; SuarezMena et al., 2015).

Rumen digesta retained $\mathrm{X}_{\mathrm{gm}}$ at slaughter time (12 to $14 \mathrm{~h}$ after feeding; Table 5) was lower for PS than SS, MS, and LS; this was a result of a lower proportion of particles retained on the $3.35-\mathrm{mm}$ sieve for PS than in the 3 other treatments, which was compensated by greater proportions retained on the 3 lower sieves for PS.

\section{Particle Size, Starch Content, and pH of Feces}

Particle size, starch content, and $\mathrm{pH}$ of feces measured in trial 1 are presented in Table 6 . Total and retained $\mathrm{X}_{\mathrm{gm}}$ of feces were not affected by diet, but the proportion of retained particles on the $3.35-\mathrm{mm}$ sieve linearly increased $(P=0.03)$ as particle size did, which was compensated by a linear decrease $(P=0.01)$ in the proportion of particles retained in the $1.18-\mathrm{mm}$ sieve as particle size increased. Similar fecal $\mathrm{X}_{\mathrm{gm}}$ across diets implied that calves were able to reduce particle size of straw to the same size across diets, and this was possibly a consequence of increased ruminating activ- 
Table 5. Rumen contents particle size of calves fed starters containing $5 \%$ straw differing in particle size either in the pellet (PS) or mixed with the pellet: short (SS), medium (MS), and long straw (LS)

\begin{tabular}{|c|c|c|c|c|c|}
\hline \multirow[b]{2}{*}{ Item } & \multicolumn{4}{|c|}{ Diet } & \multirow[b]{2}{*}{$\mathrm{SEM}^{1}$} \\
\hline & PS & SS & MS & LS & \\
\hline$\overline{\mathrm{X}_{\mathrm{gm}}, \text { retained }^{2}}$ & $0.86^{\mathrm{a}}$ & $1.20^{\mathrm{b}}$ & $1.31^{\mathrm{b}}$ & $1.19^{\mathrm{b}}$ & 0.09 \\
\hline $\mathrm{S}_{\mathrm{gm}}$, retained $^{2}$ & $1.14^{\mathrm{a}}$ & $1.20^{\mathrm{b}}$ & $1.22^{\mathrm{bc}}$ & $1.24^{\mathrm{c}}$ & 0.01 \\
\hline \multicolumn{6}{|c|}{ Retained, $\%$ of DM } \\
\hline $3.35-\mathrm{mm}$ sieve & $3.57^{\mathrm{a}}$ & $17.66^{\mathrm{b}}$ & $24.71^{\mathrm{b}}$ & $24.10^{\mathrm{b}}$ & 3.58 \\
\hline 1.18-mm sieve & 14.25 & 16.38 & 13.06 & 10.19 & 2.08 \\
\hline 1.00-mm sieve & 6.14 & 5.62 & 5.65 & 4.86 & 0.61 \\
\hline 0.85 -mm sieve & 5.27 & 4.56 & 4.24 & 3.50 & 0.62 \\
\hline $0.60-\mathrm{mm}$ sieve & $18.16^{\mathrm{a}}$ & $14.58^{\mathrm{b}}$ & $13.21^{\mathrm{b}}$ & $13.37^{\mathrm{b}}$ & 0.71 \\
\hline $0.425-\mathrm{mm}$ sieve & $20.98^{\mathrm{a}}$ & $16.71^{\mathrm{b}}$ & $15.44^{\mathrm{b}}$ & $16.12^{\mathrm{b}}$ & 0.98 \\
\hline 0.15 -mm sieve & $31.64^{\mathrm{a}}$ & $24.49^{\mathrm{b}}$ & $23.69^{\mathrm{b}}$ & $27.85^{\text {ab }}$ & 2.19 \\
\hline
\end{tabular}

ity as particle size increased. Hodgson (1971) observed calves spent longer times ruminating with greater diet particle size. In adult cattle, longer time spent ruminating increases saliva production and buffers rumen $\mathrm{pH}$ (Krause and Oetzel, 2006); however, we did not detect an effect of diet on rumen $\mathrm{pH}$ in the present study. Lack of differences in fecal particle size contrasts with shorter rumen contents particle size of PS and further supports the idea that calves had to spend more time or be more efficient at ruminating as particle size increased. Fecal pH was not statistically different between diets; however, the 2 diets with longest particle size had numerically higher $(P=0.13) \mathrm{pH}$ than the other 2 diets. Castells et al. (2013) observed that calves supplemented with oat hay had lower rectum $\mathrm{pH}$ than calves fed concentrates only or supplemented with alfalfa hay $(5.90,6.40$, and 6.48 , respectively); these values are not far from those observed in the present study. Fecal starch concentration increased whereas $\mathrm{pH}$ decreased as calves aged (Figure 5), similar to our earlier study (Suarez-Mena et al., 2015); starch increase is likely a consequence of an increased passage rate due to higher intake. Other workers have also found a negative correlation between fecal $\mathrm{pH}$ and starch concentration in steers, lambs, older calves (Wheeler and Noller, 1977), and yearling heifers (Depenbusch et al., 2008). The decrease in fecal $\mathrm{pH}$ is responsive to greater amounts of starch being fermented in the hindgut (Depenbusch et al., 2008). The proportion of feces' soluble fraction decreased with age $(84.7,79.0,72.7,67.8,64.2$, and $59.9 \%$ for wk 1 to 6 from the time starter was available, respectively) likely a result of less DM coming from MR as starter intake increased. The lack of an age response in retained $\mathrm{X}_{\mathrm{gm}}$, in spite of greater proportions of fecal DM being retained, suggests that calves were able to reduce particle size of starter to the same degree as starter intake increased.

\section{Digestive Organ Measurements}

Slaughter measurements and rumen development parameters are presented in Table 7 . Organ weights, their proportion of $\mathrm{BW}$, and rumen development parameters differ between trials likely because calves in trial 1 were older at slaughter and had greater starter intake. Particle size did not affect reticulorumen and abomasum weights, in agreement with other reports (Greenwood et al., 1997; Beharka et al., 1998). Greenwood et al. (1997) suggested that, in their study, similar reticulorumen weights were expected because of similar intakes; this could also apply to our study because, as in theirs, the only treatment difference was particle size of starter and intake was similar across treatments. Xylose absorption was greater for LS versus SS and MS, but not SS.

When the omasum was analyzed as a percentage of BW at harvest it decreased linearly as particle size increased; others have also reported heavier omasums for diets with smaller particle size (Greenwood et al., 1997; Beharka et al., 1998). This observation was attributed to an increased flow of particles with shorter particle size from rumen to omasum (Beharka et al., 1998) and to greater muscular development (Greenwood et al., 1997). Stevens et al. (1960) described the omasum as a 2 -stage pump that transfers digesta from the reticulum to the abomasum. In the first stage, the omasal canal vacuums reticulum contents into the canal and pumps them into the omasal body; these 2 contractions are synchronized to primary and secondary rumen contractions. In the second stage, the omasal body contracts, 
Table 6. Starch concentration, $\mathrm{pH}$, and fecal particle size of calves fed starters containing $5 \%$ differing in particle size either in the pellet (PS) or mixed with the pellet: short (SS), medium (MS), and long straw (LS) in trial 1

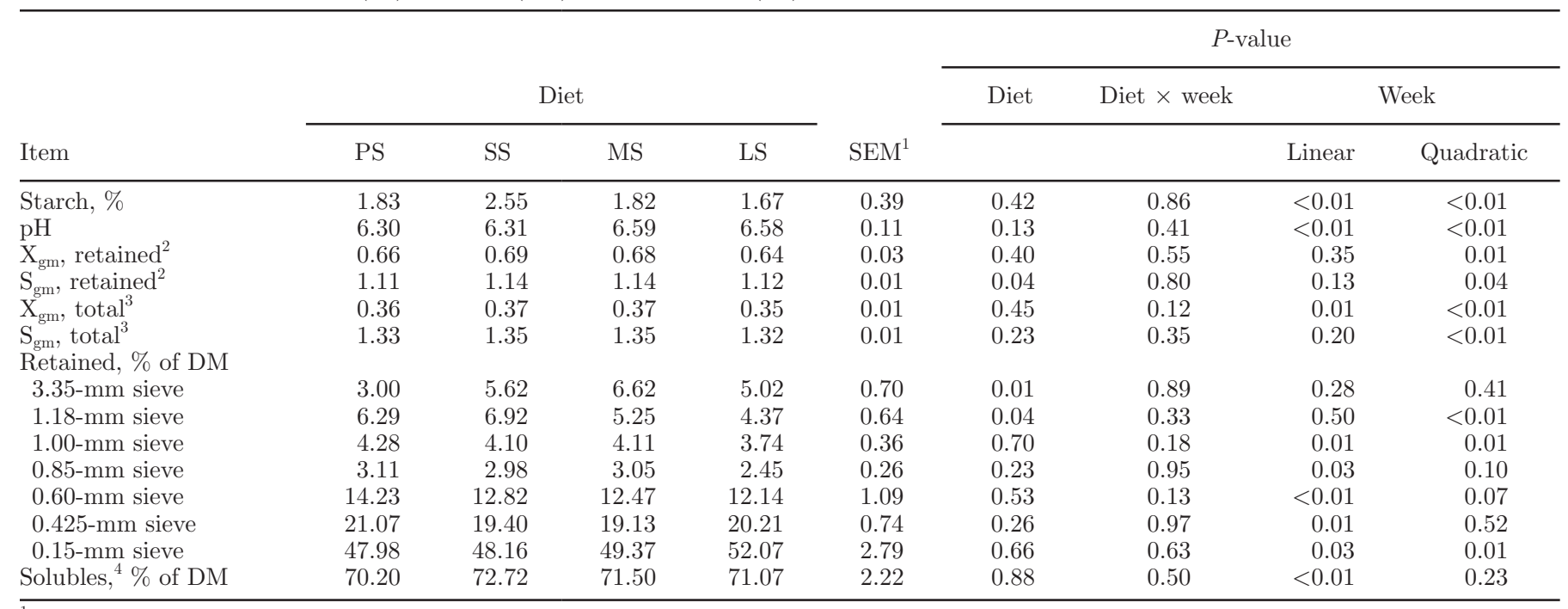

${ }^{1}$ Because of unequal animal numbers SE differ between treatments, the highest SEM were reported in the table.

${ }^{2}$ Geometric mean $\left(\mathrm{X}_{\mathrm{gm}}\right)$ and standard deviation $\left(\mathrm{S}_{\mathrm{gm}}\right)$ of particle length as calculated by ASABE (2007) using data from screens $\geq 0.15 \mathrm{~mm}$. Particles retained on the top screen were assumed to be $4.7 \mathrm{~mm}$ long.

${ }^{3}$ Geometric mean $\left(\mathrm{X}_{\mathrm{gm}}\right)$ and standard deviation $\left(\mathrm{S}_{\mathrm{gm}}\right)$ of particle length as calculated by ASABE (2007) using data from all particle fractions. Particles retained on the top screen were assumed to be $4.7 \mathrm{~mm}$ long.

${ }^{4}$ Proportion of particles that passed through the bottom screen.

pumping digesta into the abomasum or back to the reticulum; omasal body contractions do not necessary occur in synchrony with reticulo-omasal cycles and seem to be initiated by digesta accumulation between omasal leaves (Stevens et al., 1960). We hypothesized

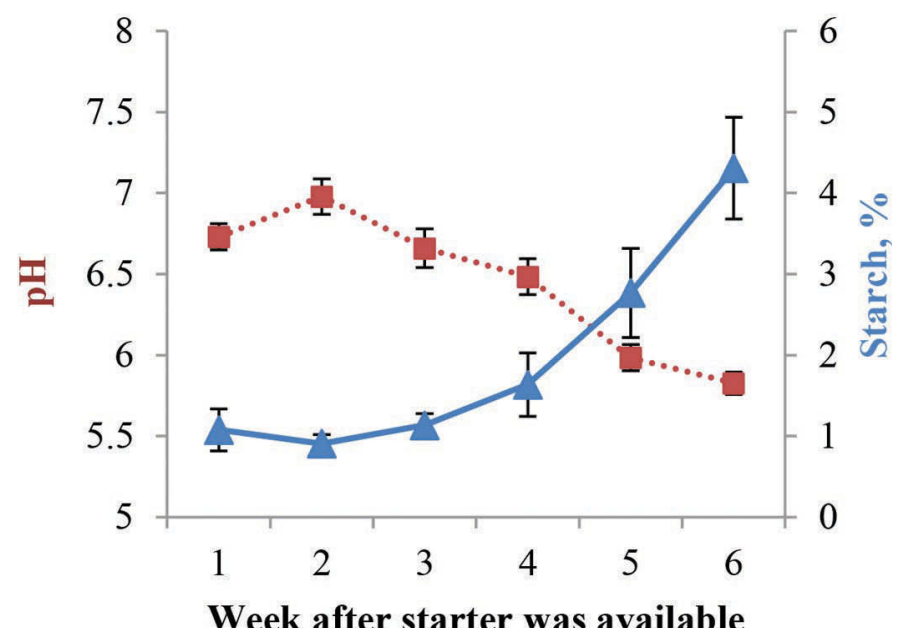

Figure 5. Mean fecal pH $(\mathbf{\square})$ and $\operatorname{starch}(\boldsymbol{\Delta})$ concentration from 1 to 6 wk after starter was available for calves fed starter containing $5 \%$ straw differing in particle size either in the pellet (PS) or mixed with the pellet: short (SS), medium (MS), and long straw (LS). Linear effect of week, $P<0.01$ for both variables. Color version available online. that small feed particles accumulate between omasal leaves when the particle size of the diet does not provide enough abrasion. Accumulation of particles increases omasum size by distending the omasal body and by greater muscle growth in response to increased omasal body contractions. We observed fully distended omasums with a hard to remove, paste-like matter between omasal leaves in several calves.

Rumen development measures of papillae length and width and rumen wall thickness were not affected by particle size. Beharka et al. (1998) reported greater length in the dorsal and blind sacs with greater diet particle size, whereas Greenwood et al. (1997) observed a decrease papillae length in the ventral floor of the cranial sac as particle size increased. Conflicting results between these studies could be related to sampling location. In the present study, papillae were measured from 9 locations, including all sacs, and the interaction between diet and location was not significant $(P>0.1)$. Fokkink et al. (2011) observed longer papillae when a starter greater in particle size was fed and calves had similar straw intakes; however, nutrient composition differed between starters. Castells et al. (2013) observed that calves supplemented with oat hay had shorter papillae than calves fed concentrates only when keratin layer was similar, yet calves had access to eat bedding. Calves in the Beharka et al. (1998) study were kept on diets for about 11 wk and fed milk 
Table 7. Digestive system development measurements in calves fed starters containing $5 \%$ straw differing in particle size either in the pellet (PS) or mixed with the pellet: short (SS), medium (MS), and long straw (LS)

\begin{tabular}{|c|c|c|c|c|c|c|c|c|c|c|}
\hline \multirow[b]{3}{*}{ Item } & \multirow{2}{*}{\multicolumn{4}{|c|}{ Diet }} & \multirow[b]{3}{*}{$\mathrm{SEM}^{1}$} & \multicolumn{5}{|c|}{$P$-value } \\
\hline & & & & & & \multirow[b]{2}{*}{ Diet } & \multirow[b]{2}{*}{ Trial } & \multirow[b]{2}{*}{ Diet $\times$ trial } & \multicolumn{2}{|c|}{ Diet } \\
\hline & PS & SS & MS & LS & & & & & Linear & Quadratic \\
\hline $\begin{array}{l}\text { Xylose, } \mathrm{mg} / \mathrm{dL} \\
\text { Slaughter data }\end{array}$ & \multicolumn{9}{|c|}{ Slaughter data } & $<0.01$ \\
\hline Carcass, $\mathrm{kg}$ & 47.9 & 47.2 & 46.4 & 49.4 & 1.6 & 0.57 & 0.08 & 0.44 & 0.59 & 0.25 \\
\hline Reticulorumen, g & 721 & 766 & 688 & 742 & 45 & 0.65 & $<0.01$ & 0.88 & 0.93 & 0.92 \\
\hline Omasum, g & 245 & 217 & 206 & 200 & 17 & 0.27 & $<0.01$ & 0.97 & 0.06 & 0.52 \\
\hline Abomasum, g & 265 & 292 & 264 & 265 & 11 & 0.25 & $<0.01$ & 0.98 & 0.58 & 0.24 \\
\hline Liver, $\mathrm{g}$ & 1,135 & 1,146 & 1,083 & 1,107 & 43 & 0.73 & $<0.01$ & 0.95 & 0.44 & 0.88 \\
\hline Spleen, g & 167 & 177 & 159 & 170 & 10 & 0.63 & 0.01 & 0.70 & 0.83 & 0.99 \\
\hline \multicolumn{11}{|c|}{ Organ proportion of BW at harvest } \\
\hline Reticulorumen, \% & 1.10 & 1.17 & 1.06 & 1.09 & 0.05 & 0.55 & $<0.01$ & 0.74 & 0.54 & 0.65 \\
\hline Omasum, \% & 0.38 & 0.33 & 0.32 & 0.29 & 0.02 & 0.06 & $<0.01$ & 0.62 & 0.01 & 0.67 \\
\hline Abomasum, \% & 0.41 & 0.45 & 0.42 & 0.39 & 0.02 & 0.20 & 0.03 & 0.69 & 0.40 & 0.06 \\
\hline Liver, \% & 1.76 & 1.75 & 1.71 & 1.64 & 0.05 & 0.29 & $<0.01$ & 0.39 & 0.08 & 0.47 \\
\hline Spleen, \% & 0.26 & 0.27 & 0.25 & 0.25 & 0.01 & 0.50 & 0.19 & 0.35 & 0.46 & 0.69 \\
\hline Papillae length, mm & 0.84 & 0.79 & 0.77 & 0.80 & 0.06 & 0.85 & 0.04 & 0.84 & 0.54 & 0.52 \\
\hline Papillae width, mm & 0.49 & 0.49 & 0.48 & 0.46 & 0.02 & 0.57 & $<0.01$ & 0.59 & 0.22 & 0.54 \\
\hline $\mathrm{RWT},{ }^{2} \mathrm{~mm}$ & 0.79 & 0.79 & 0.80 & 0.76 & 0.07 & 0.97 & $<0.01$ & 0.90 & 0.80 & 0.74 \\
\hline
\end{tabular}

$\stackrel{\circ}{5}{ }^{1}$ Because of unequal animal numbers, SEM differ between treatments; the highest SEM are reported in the table.

$\stackrel{2}{2} \mathrm{RWT}=$ rumen wall thickness. 
to $8 \%$ of $\mathrm{BW}$; hence, calves' solid feed intake was likely very high, which would intensify the effects of starter particle size. Also, the diet shorter in particle size had $20.5 \%$ of particles $>0.99 \mathrm{~mm}$, much less than the recommended $50 \%$ of particles $>1.19 \mathrm{~mm}$ to ensure adequate intake, proper rumen fermentation (Warner et al., 1973), and prevent physiological abnormalities (Porter et al., 2007) up to 8 wk of age for calves fed no hay and without access to consuming bedding materials. In the Greenwood et al. (1997) study, the shorter particle size starter had $15.9 \%$ of particles $>1.7 \mathrm{~mm}$ and $50.8 \%>0.85 \mathrm{~mm}$, which likely did not meet Warner et al. (1973) recommendations either. Nevertheless, Warner et al. (1973) did not measure the keratin layer in their study for making suggestions. It is clear from these findings that calves do need a certain amount of large particles for healthy rumen development and papillae growth, yet this requirement is dependent on several factors, including diet ingredient composition and solid feed intake. It is possible that, in the present study, even when particle size of PS diet did not meet Warner et al. (1973) parameters and calves were on experimental diets for the same length of time and had comparable intakes to Greenwood et al. (1997) study, that PS particle size met the abrasiveness requirement for healthy papillae growth and thus increasing straw particle size had no effect on papillae length and rumen development parameters.

\section{CONCLUSIONS}

Increasing the particle size of starter by changing the particle size of straw at a $5 \%$ inclusion rate resulted in minimal changes in ruminal fermentation, no effect on fecal particle size, $\mathrm{pH}$, and starch content, and no change in rumen development parameters. The size of the omasum decreased as particle size increased; the implications of this change may be beneficial to the calf and need to be elucidated. Under the conditions of this study, increasing the particle size of low-quality forage to calf diets did not improve rumen development parameters or provided with a more stable rumen fermentation.

\section{REFERENCES}

Anderson, K. L., T. G. Nagaraja, and J. L. Morrill. 1987. Ruminal metabolic development in calves weaned conventionally or early. J. Dairy Sci. 70:1000-1005.

AOAC International. 2000. Official Methods of Analysis. 17th ed. AOAC International, Arlington, VA.

ASABE. 2007. Method of determining and expressing particle size of chopped forage materials by screening. ANSI/ASAE. S424. 1:663-665.
Beharka, A. A., T. G. Nagaraja, J. L. Morrill, G. A. Kennedy, and R. D. Klemm. 1998. Effects of form of the diet on anatomical, microbial, and fermentative development of the rumen of neonatal calves. J. Dairy Sci. 81:1946-1955.

Castells, L., A. Bach, A. Aris, and M. Terré. 2013. Effects of forage provision to young calves on rumen fermentation and development of the gastrointestinal tract. J. Dairy Sci. 96:5226-5236.

Chaney, A. L., and E. P. Marbach. 1962. Modified reagents for determination of urea and ammonia. Clin. Chem. 8:130-132.

Coverdale, J. A., H. D. Tyler, J. D. Quigley, and J. A. Brumm. 2004. Effect of various levels of forage and form of diet on rumen development and growth in calves. J. Dairy Sci. 87:2554-2562.

Davis, C. L., and J. K. Drackley. 1998. The Development, Nutrition, and Management of the Young Calf. Iowa State Univ. Press, Ames.

Depenbusch, B. E., T. G. Nagaraja, J. M. Sargeant, J. S. Drouillard, E. R. Loe, and M. E. Corrigan. 2008. Influence of processed grains on fecal $\mathrm{pH}$, starch concentration, and shedding of Escherichia coli O157 in feedlot cattle. J. Anim. Sci. 86:632-639.

Flatt, W. P., R. G. Warner, and J. K. Loosli. 1958. Influence of purified materials on the development of the ruminant stomach. J. Dairy Sci. 41:1593-1600.

Fokkink, W. B., T. M. Hill, H. G. Bateman, J. M. Aldrich, R. L. Schlotterbeck, and A. F. Kertz. 2011. Case study: Effect of highand low-cereal-grain starters on straw intake and rumen development of neonatal Holstein calves. Prof. Anim. Sci. 27:357-364.

Goering, H. K., and P. J. Van Soest. 1970. Forage Fiber Analyses (Apparatus, Reagents, Procedures, and Some Applications). Agric. Handbook No. 379. ARS-USDA, Washington, DC.

Greenwood, R. H., J. L. Morrill, E. C. Titgemeyer, and G. A. Kennedy. 1997. A new method of measuring diet abrasion and its effect on the development of the forestomach. J. Dairy Sci. 80:2534-2541.

Hinders, R. G., and F. G. Owen. 1965. Relation of ruminal parakeratosis development to volatile fatty acid absorption. J. Dairy Sci. 48:1069-1073

Hodgson, J. 1971. The development of solid food intake in calves. 1. The effect of previous experience of solid food, and the physical form of the diet, on the development of food intake after weaning. Anim. Sci. 13:15-24.

Karkalas, J. 1985. An improved enzymic method for the determination of native and modified starch. J. Sci. Food Agric. 36:1019-1027.

Khan, M. A., D. M. Weary, and M. A. G. von Keyserlingk. 2011. Hay intake improves performance and rumen development of calves fed higher quantities of milk. J. Dairy Sci. 94:3547-3553.

Krause, K. M., and G. R. Oetzel. 2006. Understanding and preventing subacute ruminal acidosis in dairy herds: A review. Anim. Feed Sci. Technol. 126:215-236.

Laarman, A. H., T. Sugino, and M. Oba. 2012. Effects of starch content of calf starter on growth and rumen $\mathrm{pH}$ in Holstein calves during the weaning transition. J. Dairy Sci. 95:4478-4487.

Lesmeister, K. E., and A. J. Heinrichs. 2004. Effects of corn processing on growth characteristics, rumen development, and rumen parameters in neonatal dairy calves. J. Dairy Sci. 87:3439-3450.

Lesmeister, K. E., P. R. Tozer, and A. J. Heinrichs. 2004. Development and analysis of a rumen tissue sampling procedure. J. Dairy Sci. $87: 1336-1344$

Maulfair, D. D., M. Fustini, and A. J. Heinrichs. 2011. Effect of varying total mixed ration particle size on rumen digesta and fecal particle size and digestibility in lactating dairy cows. J. Dairy Sci. 94:3527-3536.

Maulfair, D. D., and A. J. Heinrichs. 2010. Technical note: Evaluation of procedures for analyzing ration sorting and rumen digesta particle size in dairy cows. J. Dairy Sci. 93:3784-3788.

McGavin, M. D., and J. L. Morrill. 1976. Scanning electron microscopy of ruminal papillae in calves fed various amounts and forms of roughage. Am. J. Vet. Res. 37:497-508.

Merritt, A. M., and P. Duelly. 1983. Phloroglucionol microassay for plasma xylose in dogs and horses. Am. J. Vet. Res. 44:2184-2185.

Owens, F. N., D. S. Secrist, W. J. Hill, and D. R. Gill. 1998. Acidosis in cattle: A review. J. Anim. Sci. 76:275-286. 
Porter, J. C., R. G. Warner, and A. F. Kertz. 2007. Effect of fiber level and physical form of starter on growth and development of dairy calves fed no forage. Prof. Anim. Sci. 23:395-400.

Quigley, J. D., T. M. Steen, and S. I. Boehms. 1992. Postprandial changes of selected blood and ruminal metabolites in ruminating calves fed diets with or without hay. J. Dairy Sci. 75:228-235.

Robertson, J. B., and P. J. Van Soest. 1981. The detergent system of analysis and its application to human foods. Pages 123-158 in The Analysis of Dietary Fiber in Foods. W. P. T. James and O. Theander, ed. Marcel Dekker Inc., New York, NY.

Stevens, C. E., A. F. Sellers, and F. A. Spurrell. 1960. Function of the bovine omasum in ingesta transfer. Am. J. Physiol. 198:449-455.

Stobo, I. J. F., J. H. B. Roy, and H. J. Gaston. 1966. Rumen development in the calf. 1. The effect of diets containing different proportions of concentrate to hay on rumen development. Br. J. Nutr. 20:171-188.

Suarez-Mena, F. X., A. J. Heinrichs, C. M. Jones, T. M. Hill, and J. D. Quigley. 2015. Digestive development in neonatal dairy calves with either whole of ground oats in the calf starter. J. Dairy Sci. 98:3417-3431.
Tamate, H., A. D. McGilliard, N. L. Jacobson, and R. Getty. 1962. Effect of various dietaries on the anatomical development of the stomach in the calf. J. Dairy Sci. 45:408-420.

Thomas, D. B., and C. E. Hinks. 1982. The effect of changing the physical form of roughage on the performance of the early-weaned calf. Anim. Prod. 35:375-384.

Van Soest, P. J., J. B. Robertson, and B. A. Lewis. 1991. Methods for dietary fiber, neutral detergent fiber, and nonstarch polysaccharides in relation to animal nutrition. J. Dairy Sci. 74:3583-3597.

Warner, R. G., J. C. Porter, and S. T. Slack. 1973. Calf starter formulation for neonatal calves fed no hay. Pages 116-122 in Proc. Cornell Nutr. Conf. Cornell University, Ithaca, NY.

Wheeler, W. E., and C. H. Noller. 1977. Gastrointestinal tract pH and starch in feces of ruminants. J. Anim. Sci. 44:131-135.

Yang, C.-M. J., and G. A. Varga. 1989. Effect of three concentrate feeding frequencies on rumen protozoa, rumen digesta kinetics, and milk yield in dairy cows. J. Dairy Sci. 72:950-957. 